\title{
Ultra-depleted mantle at the Southwest Indian Ridge: The Marion Rise
}

\author{
DOMINIC WÖLKI ${ }^{1}$ AND VINCENT SALTERS ${ }^{2}$
}

\author{
${ }^{1}$ National High-Magnetic Field Laboratory, Florida State \\ University \\ ${ }^{2}$ National High-Magnetic Field Laboratory \\ Presenting Author: dominic.woelki@fau.de
}

The Marion Rise (MR) at the Southwest Indian Ridge (SWIR) is one of the slowest spreading ridges with some of the thinnest oceanic crust and shallow ridge depth, low volcanic activity and oceanic mantle exposed on the ocean floor. This provides opportunity to investigate the heterogeneity of oceanic mantle in combination with basalts. The SWIR east of the Marion Rise is deeper and has wide areas of exposed peridotite (Sauter et al., 2013). Oceanic rises are the result of higher temperature, resulting in high melt production, thick crust and elevated topography. The MR with elevated topography is an exception and mantle composition is potentially an important factor controlling MR ridge depth (Zhou and Dick, 2013a). If composition influences ridge depth, shallower ridges are underlain by less dense, i.e. more depleted, asthenosphere than at deeper ridges.

We analyzed peridotite clinopyroxenes from the MR, showing large variations along the OIB-MORB array tending to more radiogenic values with $\epsilon_{\mathrm{Nd}}$ up to 14.0 and $\epsilon_{\mathrm{Hf}}$ up to 27.3 and extend to extreme $\epsilon_{\mathrm{Nd}}$ values of 93.7 and $\epsilon_{\mathrm{Hf}}$ of 451.5. These values are the most extreme values measured for oceanic mantle and confirms the ultra-depleted nature of the MR. The MR basalts show large variations in Hf-Nd isotopic compositions, with some tending towards highly radiogenic $\epsilon_{\mathrm{Nd}}$ up to 9.1 and $\epsilon_{\mathrm{Hf}}$ up to 25.2. On the other hand, highly vesicular off-axis basalts (VOAB) were recently found at the MR which tend towards low $\epsilon_{\mathrm{Nd}}$ of -8.0 and $\epsilon_{\mathrm{Hf}}$ of -8.7 , overlapping with crustal granulite samples from the African craton. Basalts erupting on the MR seem to be a mixture of several lithologies, with one showing unradiogenic Hf-Nd isotope systematics. Apart from documenting the heterogeneous nature of the MORB mantle, it also indicates that in addition to MORB-like mantle a by far more depleted mantle exist. The depleted isotope signatures of the peridotites indicate the presence of ancient residual lithosphere (ReLish). This depleted less dense mantle contains small portions of more enriched components which all contribute to the MR, explaining the shallow ridge depths and high heterogeneity along the rise. 